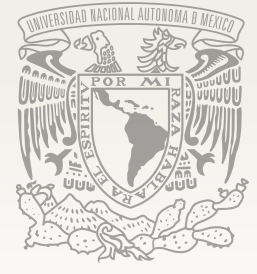

\title{
RITUAL Y MEMORIA HISTÓRICA: EL XIX ANIVERSARIO DE LA REPOBLACIÓN DEL MUNICIPIO DE SAN ANTONIO DE LOS RANCHOS EN EL SALVADOR ${ }^{1}$
}

\author{
Carlos Benjamín Lara Martínez \\ cblara@yahoo.com.mx \\ Universidad de El Salvador
}

\section{RESUMEN}

En la presente colaboración se analiza el xix Aniversario de la Repoblación de San Antonio de Los Ranchos como un ritual político relacionado con seres y fuerzas de la sociedad humana, a través del cual se hace patente la memoria histórica. Siguiendo los postulados de Turner sobre el ritual, y a Bajtin, se postula que dichos rituales crean y recrean valores y normas sociales que están en debate y contienda con «los otros». Se plantea como hipótesis que aunque en San Antonio de Los Ranchos en el momento en que se realizó esta investigación (2003-2007) existían diferencias de poder social, esta población se unificaba en virtud de su oposición y conflicto en contra de los defensores de la sociedad capitalista dominante, los cuales se encontraban fuera de su municipio. Es por ello, se concluye, que este ritual transmite una serie de valores que orienta a los sujetos sociales a la construcción de una sociedad más solidaria, equitativa y participativa. No obstante, dicha orientación es una visión utópica.

Palabras Clave: ritual, memoria histórica, liminaridad, guerra civil, FMLN

\section{RITUAL AND REMEMBRANCE: THE XIX ANNIVERSARY OF THE REPOPULATION OF THE MUNICIPALITY OF SAN ANTONIO DE LOS RANCHOS, EL SALVADOR}

\section{ABSTRACT}

This article analyzes the xix Anniversary of the Repopulation of San Antonio de Los Ranchos as a political ritual related with beings and forces of human society, through which the historical memory become evident. Following the tenets of Turner on ritual, and Bakhtin, it is proposed that these rituals create and recreate social values and norms that are in debate and struggle with «the others». It is hypothesized that even when there were differences in social power within San Antonio de Los Ranchos its population was unified against the advocates of the dominant capitalist society settled outside of the municipality. It is then concluded that this ritual communicates a set of values that guides such social subjects to build a more cohesive society, equitable and participatory. However, this guidance is a utopian vision.

Key words: ritual, historical memory, threshold, civil war, FMLN.

\footnotetext{
${ }^{1}$ Este artículo es parte de un trabajo más amplio que estoy realizando en el programa de Doctorado de la Universidad Nacional Autónoma de México, el cual indaga sobre el proceso de construcción de la «Memoria Histórica del Movimiento Campesino de Chalatenango», en la zona central-norte de El Salvador. Esta zona se constituyó en un bastión del movimiento campesino revolucionario que surgió a partir de 1970. El trabajo de campo se realizó en los años 2003, 2006 y 2007. Este artículo fue presentado originalmente como ponencia en el IX Congreso Centroamericano de Antropología, celebrado en la ciudad de Guatemala en 2013.
} 


\section{APERTURA}

Un elemento fundamental en la construcción de la memoria histórica de los semicampesinos 2 del municipio de San Antonio de Los Ranchos es la ritualización de la memoria, esto es, la celebración de actividades rituales que fijan y desarrollan la memoria de los sujetos sociales sobre su propia historia. ${ }^{3}$

Tomo el concepto de Víctor Turner (1980: 21) según el cual la actividad ritual constituye «una conducta formal prescrita en ocasiones no dominada por la rutina tecnológica, y relacionada con la creencia en seres o fuerzas místicas». En este caso, estamos hablando de rituales políticos, los cuales están relacionados con seres y fuerzas de la sociedad humana.

$\mathrm{Al}$ igual que el religioso, el ritual político está constituido por símbolos, que representan unidades discretas relacionadas entre sí y conforman sistemas. Son estas unidades estructuradas las que transmiten contenidos culturales perti-

${ }^{2}$ Utilizo el concepto de semicampesinos debido a que los pequeños agricultores de San Antonio de Los Ranchos, en el oriente de Chalatenango, combinan la agricultura de subsistencia, propia de la economía campesina, con la economía capitalista monetarizada, a través de las remesas que reciben de sus parientes que viven en los Estados Unidos de América. Esta condición de semicampesinos no es nueva para estos pequeños agricultores, pues ya en los años sesenta combinaban la agricultura de subsistencia, basada en la producción de granos básicos a pequeña escala, con su contratación temporal como fuerza de trabajo asalariada en las cortas de café y caña de azúcar. Ahora, después del conflicto político-militar que inició en la década de 1970, continúan siendo semicampesinos, combinando la agricultura de subsistencia con las remesas que les llegan de los Estados Unidos.

${ }^{3}$ Entiendo por memoria colectiva o social la manera como los sujetos sociales interpretan su propia historia. Sin embargo, si bien tradicionalmente la memoria colectiva o social ha emanado directamente del devenir de la vida social cotidiana, en la sociedad contemporánea la memoria colectiva incorpora planteamientos y conceptos de las ciencias sociales, los cuales han sido introducidos por la escuela, la Iglesia católica a través de la teología de la liberación y las organizaciones y los partidos políticos. A esta memoria colectiva o social que incorpora planteamientos y conceptos de las ciencias sociales y sobre todo de la historia científica, denomino memoria histórica, pues constituye un discurso híbrido, que si bien es fundamentalmente un discurso de la memoria colectiva ya incorpora planteamientos y conceptos de las ciencias sociales. nentes para la sociedad en la que se construye el ritual de la memoria.

Los contenidos culturales que transmite el ritual de la memoria son valores y normas sociales que orientan la vida cotidiana de los individuos y se transmiten por medio de los símbolos correspondientes, los cuales representan las unidades más elementales del ritual con significado pleno.

$\mathrm{Al}$ igual que en el discurso oral, los contenidos que construyen los sujetos sociales en los rituales políticos tienen un carácter dialógico (Bajtín 1992), en el sentido de que al participar crean y recrean valores y normas sociales que están en debate y contienda con «los otros». Dado que los semicampesinos de Los Ranchos son sujetos revolucionarios que participaron en el movimiento popular generado a partir de 1970, «los otros» están representados por los defensores del sistema capitalista dominante. La actividad ritual y, en específico, los símbolos rituales, no pueden entenderse si no es en este marco de interacción social, esto es, de oposición y conflicto entre el nosotros y los otros.

Esto supone que el ritual no puede entenderse si no es a partir de los sujetos sociales que lo producen. Estos construyen un campo de poderes, como lo establece Víctor Turner (1980), en el sentido de que quienes participan en la organización y en la realización del ritual buscan imponer su voluntad sobre otros grupos sociales o individuos, ya sea que tengan igual o menor cuota de poder social o incluso que estén en una posición de superioridad.

Es por ello que la decisión de realizar un ritual conduce a la constitución de un campo de fuerzas en el cual los sujetos sociales compiten por los papeles e intentan imponer un significado determinado. En este sentido, establezco como hipótesis que aunque en San Antonio de Los Ranchos, en el momento en que se realizó esta investigación (2003-2007) existían diferencias de poder social, la población se unificaba en virtud de su oposición y conflicto respecto de los defensores de la sociedad capitalista dominante, los cuales se encontraban fuera de su municipio. ${ }^{4}$

${ }^{4}$ Aunque se detectaron algunos individuos de derecha en San Antonio de Los Ranchos, estos eran muy minorita- 
Pero la realización de un ritual es trascendente para la configuración del poder social en una población determinada. El alcalde de Los Ranchos, que para 2007 ya llevaba cuatro periodos, y los directivos de la Asociación de Desarrollo Comunitario (ADESCO) se legitimaban por medio de los rituales de la memoria. Aunque estos líderes locales tenían oposición en el interior de sus poblaciones, esta no era tan fuerte como la pugna y el conflicto frente a los defensores del sistema capitalista dominante. Es por ello que, a pesar de las diferencias internas, Los Ranchos presentaba un fuerte sentido de unidad y de cohesión social interna y, por tanto, un discurso unificado de la memoria.

Los rituales de la memoria contribuían a mantener este sentido de unidad comunitaria y a fijar un discurso de la memoria. Como lo ha establecido Irina Silberg (2011: 64-67), las conmemoraciones ocultan las diferencias internas que han surgido en el periodo posterior al conflicto militar en las poblaciones del oriente de Chalatenango, y han fijado la figura del héroe revolucionario que enfrentó al ejército nacional y luchó por una sociedad más justa e igualitaria, se mantuvo en los campos de refugiados y repobló el oriente de Chalatenango, todo ello con un fuerte sentido de comunidad.

Pero los rituales de la memoria, sostengo como hipótesis, no solo ocultan las diferencias internas, con el objeto de reafirmar un significado de unidad y cohesión social, sino que también proporcionan un sentido de construcción de un nuevo tipo de sociedad y de cultura, más solidaria, equitativa y participativa, la cual en gran medida se ha logrado en el municipio de San Antonio de Los Ranchos.

Ahora bien, la realización de un ritual provoca una ruptura con la vida social cotidiana, esto es, supone la suspensión de las actividades económicas, políticas y sociales cotidianas o de la sociedad regular. El anuncio de la realización de un ritual de la memoria, por ejemplo, asumía que los semicampesinos suspendieran o al menos redujeran considerablemente sus activi-

rios y hasta la fecha no causaban mayor problema a los semicampesinos revolucionarios, por lo cual la oposición de estos sujetos era más hacia la sociedad nacional y mundial que hacia su propio municipio. dades cotidianas, para concentrarse en el ritual. En este sentido, todo ritual supone una fase de ruptura o separación de la vida social cotidiana, como señala Víctor Turner (1982), lo cual provoca la creación de un tiempo y un espacio especiales, sagrados o excepcionales, que no se regulan por la normativa social cotidiana o de la sociedad regular, sino que crean una propia. En consecuencia, se crea un tiempo y un espacio de tipo liminar o liminoide, en el cual se suspenden las normas de la sociedad regular y se construye una alternativa que favorece el juego con los símbolos culturales y, por tanto, la creación de formas y contenidos culturales nuevos, así como la recreación de los tradicionales. Por último, dado que se ha roto con la vida cotidiana, el ritual supone una fase de reintegración o reincorporación.

Así, propongo estudiar los rituales de la memoria con base en las tres fases que pueden observarse en toda actividad ritual: $(i)$ una de ruptura o separación, en la cual se anuncia el inicio del ritual y, por tanto, de un tiempo y un espacio especiales o de excepción; (ii) una segunda, que denominaré nuclear, pues constituye el núcleo del ritual, que representa la de liminaridad sociocultural, durante la cual se desarrolla la actividad ritual y se genera el significado esencial de la actividad simbólica; y (iii) una de reintegración a la sociedad regular o cotidiana.

El carácter liminar de estos rituales está dado por su naturaleza cíclica, es decir, por el hecho de que se realizan cada año y en la misma fecha. Uno sabe que el siguiente se va a efectuar más o menos de la misma forma en la fecha establecida. Este carácter cíclico le impone un contenido conservador, pues cuando los rituales se celebran todos los años más o menos de la misma manera, tienden a reafirmar los valores y las normas sociales dominantes más que a crear nuevos valores y normas sociales.

Se trata de un umbral sincrónico, pues los sujetos dejan la sociedad regular para retornar a ella y al mismo estatus social, a diferencia de los rituales de pasaje estudiados por Van Gennep (en Turner 1980) en donde los sujetos pasan de un estatus social determinado a otro de calidad diferente. Este carácter sincrónico del proceso liminar le imprime un toque más conservador 
a los rituales de la memoria, es decir, estos tienden más a reafirmar los valores dominantes de las comunidades de los semicampesinos revolucionarios que a transformarlos.

No obstante, hay que dejar claro que los valores y las normas sociales que estos rituales reafirman no son únicamente aquellos de la sociedad campesina tradicional del área mesoamericana, sino también los que han sido creados por medio del proceso de transformación sociocultural experimentado en estas poblaciones. En este sentido, en los valores que se están reafirmando a través de los rituales de la memoria podemos suponer que se observa la dialéctica de cambio/continuidad sociocultural, pues si bien se ocupan de valores tradicionales de la sociedad campesina mesoamericana, también ocurre eso con los de la ideología revolucionaria de estas poblaciones. ${ }^{5}$

Por otra parte, también hay que tomar en cuenta que Los Ranchos se mantiene hasta 2007 en un estado de liminaridad sociocultural, puesto que no se ha integrado del todo a la sociedad capitalista nacional y mundial, al mantener un fuerte grado de autonomía sociocultural, de cara a la construcción de una sociedad más solidaria, con mayor equidad social y con un alto grado de participación en la toma de decisiones.

En este contexto, si bien los rituales de la memoria en Los Ranchos son liminares en relación con la sociedad local, pues reafirman los valores y las normas sociales dominantes de esta población, adquieren un carácter liminoide respecto de la sociedad nacional y mundial, pues representan valores y normas revolucionarios, subversivos, que se oponen a los valores y normas dominantes del capitalismo nacional y global. ${ }^{6}$

5 Es importante aclarar que si bien los valores revolucionarios de los semicampesinos de Los Ranchos han sido valores subversivos que han transformado la cultura tradicional de estos sujetos sociales, después de los Acuerdos de Paz estos valores se han venido rutinizando (Weber, 1981 [1922]: 193-204), por lo que se han integrado a la cultura de la sociedad regular de Los Ranchos.

${ }^{6}$ En términos generales, como ya se ha establecido, la liminaridad sociocultural supone un estado de suspensión del sistema de valores y normas sociales dominante, que en el contexto de esta investigación supone la suspensión o la interrupción de los valores y las normas de la sociedad semicampesina, en parte campesina y en parte capitalista neoliberal. No obstante, a través de mi investigación de

\section{EL MUNICIPIO DE SAN ANTONIO DE LOS RANCHOS}

El municipio de San Antonio de Los Ranchos se ubica en la zona oriental del departamento de Chalatenango, en la zona central-norte de El Salvador. En el momento en que se realizó esta investigación (2003-2007) contaba con 1619 habitantes, de los cuales, 618 (38.17\%) vivían en el área urbana y 1001 (61.83\%), en el área rural. ${ }^{7}$

La mayoría de esta población no es originaria de Los Ranchos, sino que llegó del campamento de refugiados de Mesa Grande (Honduras) en 1988, en donde permanecía desde 1980. No obstante, casi todos ellos vivían en las comunidades y los municipios del oriente de Chalatenango, la microárea sociocultural a la que pertenece el municipio de Los Ranchos.

Dicho ayuntamiento, así como toda el área del oriente de Chalatenango, se vio involucrado en el conflicto político-militar que se inició a partir de 1970, durante el cual gran parte de su población se incorporó en el movimiento revolucionario, al ingresar en las filas de la Unión de Trabajadores del Campo (UTC) y más tarde en la organización guerrillera Fuerzas Populares de

campo he podido observar que los estados de liminaridad sociocultural más que crear un estado de ausencia o de confusión de valores y normas sociales, tienden a crear sistemas de valores y normas sociales alternativos al sistema dominante. Este es el caso del municipio de San Antonio de Los Ranchos, el cual se mantiene en un estado de liminaridad sociocultural, debido a que después del conflicto político-militar no se ha integrado del todo al sistema capitalista dominante, sino que ha construido su propio sistema social con base en tres procesos: (1) su tradición semicampesina —que se origina antes del conflicto político-millitar, cuando los pequeños agricultores combinaban la agricultura de subsistencia con las cortas de café y caña de azúcar-, (2) los sistemas de relaciones sociales y de símbolos culturales construidos a través del proceso revolucionario y (3) las nuevas condiciones del capitalismo global. En este contexto, si bien los rituales de la memoria adquieren un carácter liminar, en el sentido de que tienden a recrear los valores y las normas sociales dominantes de la localidad, a nivel de la sociedad nacional y global adquieren un carácter liminoide, pues cuestionan y subvierten los valores y las normas dominantes de la sociedad capitalista neoliberal, tanto por su condición semicampesina como por los valores y normas sociales que han creado a través del proceso revolucionario.

${ }^{7}$ Según los censos nacionales para El Salvador en 2007 (Ministerio de Economía et al. 2008). 

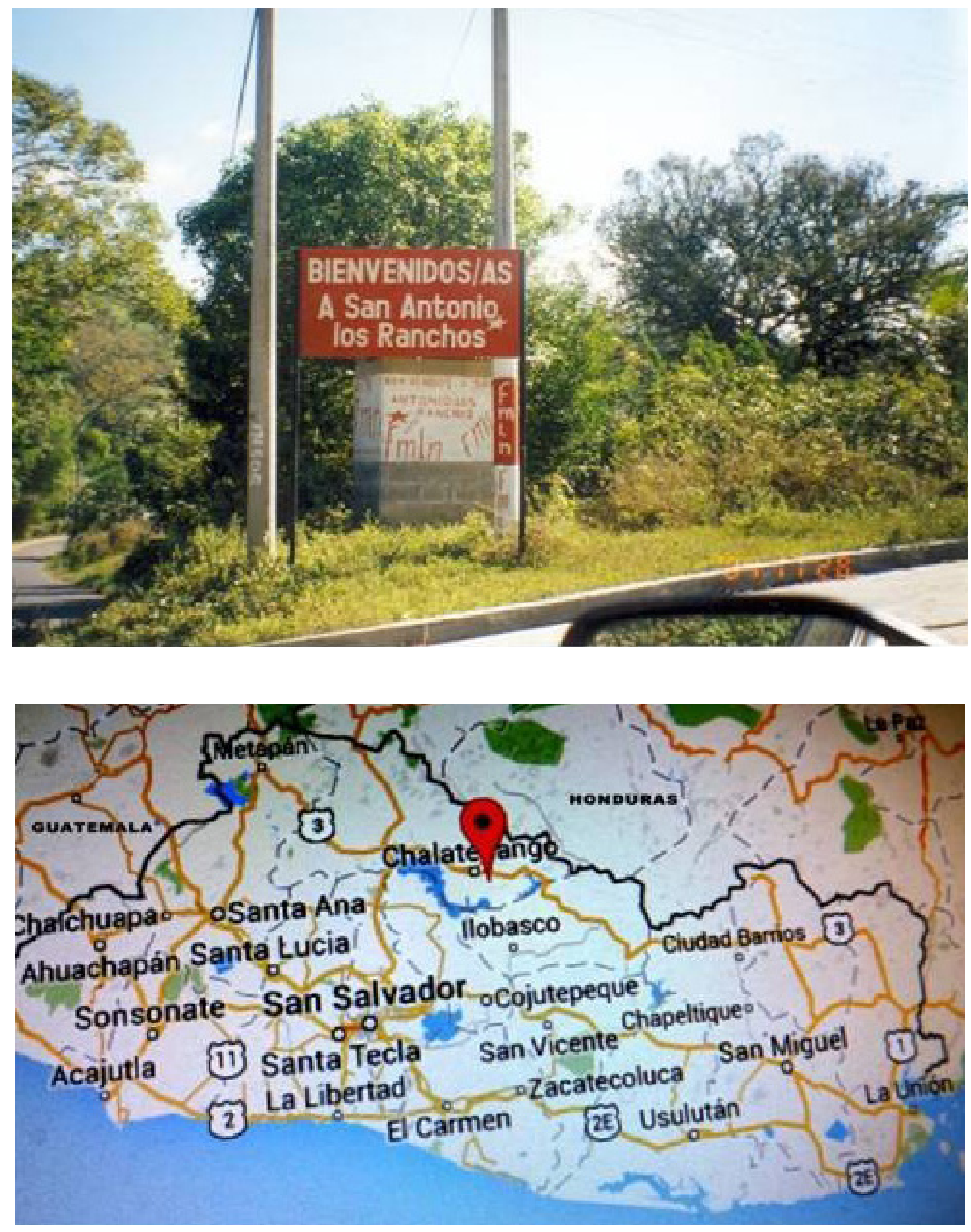

Ubicación del municipio de San Antonio de Los Ranchos 
Liberación Farabundo Martí, aunque muchos se mantuvieron como «masa» o población civil pero con un decidido apoyo a las fuerzas de la revolución. Por supuesto, un sector de esta población apoyó a los defensores del sistema capitalista dominante y otro, sencillamente no se involucró en el conflicto.

Los semicampesinos del oriente de Chalatenango se vieron obligados a abandonar sus comunidades y municipios de origen, debido a que la violencia política fue tan intensa que ya no era posible vivir en esa zona. Los semicampesinos que apoyaban a las fuerzas revolucionarias se incorporaron a la organización guerrillera o se mantuvieron deambulando por las montañas de Chalatenango o, finalmente, sobre todo las mujeres, los niños y los ancianos, aunque también algunos hombres adultos, se fueron al campamento de refugiados de Mesa Grande, en el departamento de Ocotepeque, en Honduras.

La población que actualmente habita San Antonio de Los Ranchos en su mayoría permaneció en el campamento de refugiados de Mesa Grande de 1980 a 1988, hasta que en agosto de 1988 decidieron repoblar este municipio. El viaje de retorno no fue fácil, pues el gobierno de El Salvador y las Fuerzas Armadas de este país no estaban de acuerdo con que los refugiados volvieran al oriente de Chalatenango, pues los consideraban base social de apoyo del movimiento revolucionario, mientras que el Alto Comisionado de las Naciones Unidas para los Refugiados (ACNUR) no estaba interesado en entrar en contradicción con las autoridades salvadoreñas. No obstante, los refugiados tomaron la decisión firme de repoblar el municipio de San Antonio de Los Ranchos y el 10 de agosto de 1988 emprendieron el viaje a esa tierra.

El trayecto fue dificultoso, como se verá en el relato que los propios viajeros presentaron en el xix Aniversario de la Repoblación, y al llegar a Los Ranchos se encontraron con la presencia del ejército nacional. No obstante, esto no los intimidó, y se asentaron en este municipio y comenzaron la reorganización de su comunidad, sin perder la base de organización política y social que ya tenían en Mesa Grande. El objetivo era construir un nuevo tipo de sociedad y de cultura que mejorara la calidad de vida de los semicampesinos.

El proceso de reorganización del municipio fue encabezado por la directiva de la comunidad y sus áreas de trabajo: educación, salud, comedor comunitario, vivienda, pastoral, producción y talleres. Sin embargo, entre 1988 y 1992 la situación fue inestable, pues el conflicto militar continuaba y la población de Los Ranchos pasaba de la vida comunitaria a las filas guerrilleras y viceversa. A partir de la firma de los Acuerdos de Paz comienza la construcción de un nuevo tipo de sociedad y de cultura, ahora en una situación de estabilidad política. La directiva de la comunidad adquiere la personería jurídica, y pasa a ser una Asociación de Desarrollo Comunitario (ADESCO); de ese modo, en 1994 se celebran elecciones municipales, y el recién fundado partido político Frente Farabundo Martí para la Liberación Nacional (FMLN) triunfa para ocupar el gobierno local.

Además, desde 1988 los semicampesinos del oriente de Chalatenango fundaron la Coordinadora de Comunidades y Repoblaciones (CCR) de Chalatenango, que luego cambió de nombre por Asociación de Comunidades para el Desarrollo de Chalatenango, la cual ha mantenido una coordinación efectiva entre todas las comunidades y los municipios del oriente de Chalatenango, constituyendo una verdadera defensa de los logros revolucionarios de estas poblaciones. También la Iglesia católica y algunas organizaciones no gubernamentales, como CORDES, apoyaron el proyecto social de estas localidades.

Hasta el momento en que se realizó esta investigación, San Antonio de Los Ranchos ha obtenido importantes logros revolucionarios: ha mejorado las condiciones materiales de vida de sus pobladores; los semicampesinos cuentan con tierras para trabajar y casas propias de bloque con los servicios básicos, así como clínica y escuela; también se ha generado un sistema de relaciones sociales que favorece una dinámica de solidaridad y ayuda mutua entre sus miembros. En lo político, se ha desarrollado un sistema de tipo participativo, en el cual la mayoría de sus miembros interviene en la toma de decisiones sobre los problemas más agudos del municipio. 
El hecho de que los actuales pobladores de Los Ranchos tengan el control político y social y de los órganos de poder de la localidad, como la alcaldía y la ADESCO, garantiza que este municipio tiene un importante grado de autonomía sociocultural, que se traduce en lo que Sergio Tischler Visquerra (2005) define como capacidad de autodeterminación.

Esto no quiere decir que en San Antonio de Los Ranchos no haya contradicciones internas. En primer lugar, después de 15 años de los Acuerdos de Paz ya han surgido diferencias socioeconómicas entre la población. Aunque en general los semicampesinos de Los Ranchos han mejorado sus condiciones materiales de vida, el hecho de que unos hayan logrado mejores condiciones que otros engendra contradicciones. En segundo lugar, se ha generado malestar entre la población debido a que el alcalde actual (2007) ya se ha mantenido en el poder por cuatro periodos. Por último, han surgido contradicciones entre los feligreses católicos, que son la inmensa mayoría de los semicampesinos, debido a que el sacerdote de Los Ranchos para el período 19942006 ha mantenido una posición contraria a la Teología de la liberación y la opción preferencial por los pobres. Este conflicto ya ha comenzado a disminuir con el nuevo párroco, pero la oposición entre los espiritualistas y los de la opción preferencial por los pobres sigue vigente.

No obstante estas contradicciones, San Antonio de Los Ranchos presenta un nivel de unidad y cohesión social bastante alto, si uno lo compara con otras comunidades y municipios de El Salvador y del área mesoamericana, por lo cual la oposición más importante es la que se mantiene en contra de los defensores del sistema capitalista dominante, quienes están fuera de la comunidad. Esta oposición entre semicampesinos revolucionarios y defensores del sistema capitalista dominante opaca las contradicciones internas en el municipio.

\section{ANIVERSARIO DE LA REPOBLACIÓN DE SAN ANTONIO DE LOS RANCHOS}

Del 10 al 12 de agosto de 2007 los semicampesinos recordaron su llegada y asentamiento en el municipio de Los Ranchos. El ritual fue organizado por la Alcaldía Municipal, la ADEsco y la Escuela del municipio.

El 10 de agosto a las 15:00 horas varios hombres y mujeres colaboraban en la organización de las actividades. Se concentraron en el parque cultural para elaborar los materiales que iban a utilizar en la representación del viaje de retorno al municipio. Elaboraban un cañón de 90 milímetros con un tubo de cartón, el cual pintaban de negro para que se asemejara a esta arma que utilizaron en los años del conflicto militar.

Mientras preparaban estos materiales, los semicampesinos hacían comentarios sobre el armamento que utilizaban en sus empresas militares. Comentaron que el cañón de $90 \mathrm{~mm}$ se utilizó para defender posiciones, cuando funcionaron como ejército revolucionario. ${ }^{8}$ "También se utilizaban los descartables — comentaba una informante- porque esos tiraban una vez y se botaban». Pero después, cuando ya no defendían posiciones, es decir, cuando pasaron a operar como guerrilla, ya no los utilizaban, pues era muy difícil transportarlos. «Pero el RPG-7 y el RPG-2 siempre se usaban y el lanza-granadas punto 79, el M-79, un cañoncito pequeño, siempre se usó - sostenía un informante-, pero, mire, en la guerra se le adaptó al fusil M-16 y se le llamó M-203».

Los semicampesinos revolucionarios recuerdan cuando le cambiaron al ejército el G-3 por el M-16. En la medida en que el ejército aumentaba el poder de su armamento, sostenía un excombatiente, la guerrilla hacía lo propio, pues recuperaba el armamento del ejército. «El FMLN recuperó un cañón 57 que era como el 90, pero más poderoso».

Un excombatiente sostuvo que «al RPG-7 se le adaptó granadas de 81 milímetros y se le llamó RPG-81. Ésta fue una invención de la guerrilla. También inventaron la catapulta, que era como baqueta de madera que tenía dos depósitos y disparaba como un cañón 120. Y antes de eso inventaron la colmena, que se usaba para destruir

\footnotetext{
${ }^{8}$ Aunque el movimiento revolucionario fue ante todo un movimiento guerrillero, en los años de 1982 y 1983 se operó como ejército revolucionario, realizando ataques a cuarteles y manteniendo posiciones, sin embargo, esto fue insostenible porque como ejército regular el ejército nacional estaba mejor preparado que el FMLN.
} 
los blindados, que era una caja de madera llena de explosivos por dentro y se disparaba con un aparato eléctrico».

Otro excombatiente sostenía que «después llegó el AK-47 y ese fusil tenía una gran capacidad y hasta averiaba los aviones». Este mismo informante recordaba que «en El Paraíso ${ }^{9}$ se requisó el M-203. Y después en La Montañona, en una invasión al Belloso, ${ }^{10}$ se requisó otros 203 y un 90.[...] El problema con el M-203 es que la granada no entraba por el mercado negro, sino que había que requisarla al ejército».

La conversación parecía amena. A las 5:20 pm. se inauguró la sala de arte Hermana Sofía, un pequeño museo que muestra la historia de San Antonio de Los Ranchos. Este museo fue iniciativa de la Alcaldía Municipal y la ADESCO de Los Ranchos y contó con el apoyo de un alemán que acompañó a los semicampesinos durante el conflicto político-militar. «Es un pequeño museo sobre la historia de Los Ranchos, de cómo se llegó a la comunidad y de todos los sufrimientos que se tuvieron», sostenía el alcalde de Los Ranchos. «El objetivo es que los jóvenes sepan lo que sucedió y los adultos también, porque ya dicen que ya aburre, pero lo que pasa es que se están perdiendo los valores culturales y todos los sufrimientos que se vivieron», puntualizó. El nombre de Hermana Sofía se refiere a una misionera que apoyó con mucha firmeza a los semicampesinos revolucionarios.

La sala de arte tiene varias secciones. La primera está dedicada a la Iglesia Popular, luego continúa una en que se cuenta la historia de la solidaridad internacional; en seguida se muestran unos lavaderos públicos y una vivienda de 1988. A continuación, fotos del Padre Jon Cortina, ${ }^{11}$ y después una sección dedicada a la educación popular, otra en que se presenta la vida en Mesa Grande, seguida del origen de la comunidad a partir de 1988. El recorrido termi-

\footnotetext{
${ }^{9}$ En el municipio de El Paraíso se encuentra el cuartel de la $4^{\text {a }}$ Brigada de Infantería, el cual fue atacado por los semicampesinos revolucionarios.

${ }^{10}$ El Belloso era un Batallón de Infantería de Reacción Inmediata, entrenado para enfrentar al movimiento guerrillero.

${ }^{11}$ Padre Jon Cortina: sacerdote jesuita que apoyó la reconstrucción de las comunidades y los municipios del oriente de Chalatenango.
}

na con una sección de fotos sobre el trabajo de la Hermana Sofía. En la parte central de la sala se muestra el trabajo en el área de la salud y en general el trabajo comunitario.

A las 8:00 pm. pasamos al parque central, donde se presentó un conjunto de fotografías sobre la historia de San Antonio de Los Ranchos, desde su permanencia en Mesa Grande hasta la llegada al municipio, así como sobre su situación actual. Después, se pasó un video sobre la represión en Suchitoto, en el Departamento de Cuscatlán, una zona que estaba integrada al área del oriente de Chalatenango en la época del conflicto militar. Luego se puso música tropical y este día terminó con música ranchera de la banda de la alcaldía de Apopa.

Al día siguiente (11 de agosto), la actividad comenzó a las 4:00 horas con la alegre alborada. Desde la alcaldía municipal se ponía música del refugio y se daba a conocer el programa de la ceremonia. El director de la Escuela de Los Ranchos presentó una reseña histórica, la misma que se representaría en el recorrido de la repatriación de las 16:00 horas.

Miles de salvadoreños que tuvimos que abandonar nuestros lugares de origen, huyendo de la represión del gobierno salvadoreño en los años ochenta, tuvimos que refugiarnos en nuestro hermano país Honduras, en donde permanecimos durante siete años, en los campamentos de refugiados de Mesa Grande. Luego, decidimos organizarnos para retornar a nuestro país, El Salvador, y repoblar nuestros lugares de origen, el municipio de San Antonio Los Ranchos y el Cantón Teosinte del municipio de Tejutla, Chalatenango. Con la ayuda y la protección del Alto Comisionado de las Naciones Unidas para los Refugiados, ACNUR, y otras comunidades internacionales, iglesias, que nos apoyaron.

Eran las siete y treinta minutos de la mañana del 10 de agosto pero del año 1988, cuando cientos de niños, jóvenes, adultos y ancianos, que formábamos 147 familias, iniciamos nuestro retorno. Se nos dio la primera estación, en el comando militar del ejército hondureño, en Mesa Grande, pero todos los refugiados, organizados en pequeños grupos, tuvimos que abordar una caravana de buses y camiones, con nuestras pocas pertenencias que traíamos y algunos animalitos que nos acompañaban rumbo a El Salvador. En la tranca del comando militar de Mesa Grande se nos presentó la primera 
barrera: el ejército hondureño exigía el permiso, la autorización, de los gobiernos de Honduras y El Salvador, para que los refugiados pudieran salir de los campamentos, pero el ACNUR enfrentó y explicó la decisión de esta comunidad repoblada y venció la primera barrera.

Luego, nos dirigimos hacia la frontera El Poy, a las 3:30 de la tarde llegamos a la aduana, lugar en donde se nos presentó la segunda barrera, debido a que el gobierno hondureño impedía la salida de los refugiados y el gobierno salvadoreño la entrada de sus miles de compatriotas. Además, se nos exigía una documentación de todos los retornantes y se nos amenazaba con hacer registros a la caravana. También rechazaban el acompañamiento de la solidaridad internacional, que nos había protegido en los campamentos de refugiados durante mucho tiempo, por lo cual la comunidad repobladora tuvimos que hacer una tercera estación forzada, y durante el resto del día, la noche y casi el siguiente día, a la intemperie, bajo la lluvia, el hambre, la sed, y durmiendo debajo de los buses, camiones, por fin a las tres y media del siguiente día, 11 de agosto de 1988, obtuvimos el logro de que nos dieran el paso por la frontera, después de un proceso de negociación y además recibir amenazas fuertemente sobre la guerra por parte de las autoridades del gobierno y el ejército salvadoreño, pero ya sin el acompañamiento de los hermanos de la solidaridad internacional.

Pero la repoblación unida y organizada y decidida y además feliz por ya caminar por nuestras tierras, nos dirigimos hacia nuestro primer pueblo de Chalatenango, La Palma, en donde recibimos los primeros saludos y sonrisas de nuestros hermanos chalatecos. A las cinco y treinta de la tarde de ese mismo día, once, llegamos al desvío de Tejutla, siempre con el acompañamiento del ACNUR salvadoreño, lugar en el cual nos íbamos a estacionar las dos comunidades repobladoras, para despedirnos y asegurarnos que nuestros hermanos que iban a Teosinte llegaran con el apoyo del AcNur a su destino.

Pero los funcionarios del ACNur y del gobierno salvadoreño intentaron secuestrar al coordinador general de la repoblación y abandonaron la caravana. En ese momento, simultáneamente, el encargado del bus número 1 orientó a hacer alto a toda la caravana, y también se observaba presencia militar en los alrededores. Al pasar cierto tiempo regresó el carro del ACNUR, con el coordinador general, y expresó el ACNUR una propuesta del gobierno salvadoreño, que consistía en que los hermanos que iban a repoblar el Cantón Teosinte se fueran a una hacienda que el gobierno tenía disponible para ubicarlos. Pero las comunidades unidas, decididas e indignadas, por la maniobra del gobierno y del ACNUR, sosteníamos que nuestro destino eran los lugares de origen que anticipadamente se habían publicado y negociado con las representaciones de los dos gobiernos y el ACNUR.

Todos los repobladores nos bajamos de las unidades de transporte, de los buses, y también las escasas cositas, los animalitos domésticos que nos acompañaban, para descansar y esperar que el gobierno y el ACNUR desmontaran la tercera barrera que nos habían impuesto a los repobladores, quienes lo único que pretendíamos era estar en nuestros lugares de origen y cultivar nuestras tierras para sobrevivir con nuestras familias.

Pasamos esa noche, 11 de agosto del 88, moviéndonos, entre parados, recostados, desvelándonos, todo el día, 12, 13, 14 y parte del día 15, soportando un ambiente en condiciones inhumanas, sin comida, sin agua, sin dormir, animales muriéndose, niños, adultos, ancianos enfermos, bajo la lluvia, mujeres que daban a luz a sus hijos, y todo en plena calle, con el único consuelo de unidad y lucha, para lograr nuestro destino, con el acompañamiento ya de Monseñor Medardo Gómez de la Iglesia Luterana, también representantes del Comité Nacional de Repobladores, CNR, en aquel momento pero que hoy es CRIPDES, y también la ayuda del Arzobispado de San Salvador.

Al cuarto día, 15 de agosto, dicha situación era insoportable, el desprestigio que el ACNuR y el gobierno estaba recibiendo aumentaba, la presencia de la presión internacional permitió que el gobierno cediera el pase a las dos repoblaciones. Con mucho sacrificio, los repobladores, pero dispuestos a llegar a sus lugares, aun caminando, a pesar de las amenazas de que iban a hacer un registro en la Cuarta Brigada, y también que podrían capturar compañeros y compañeras, algunos enfrentamientos armados que se escuchaban en los alrededores, tiroteos en la zona, las dos hermanas comunidades continuaron su retorno, juntas pero cada una por su destino, garantizándose mutuamente su propia llegada, y venciendo las barreras que se nos habían impuesto en el camino.

Finalmente, a las ocho de la noche del día 15 de agosto llegamos a Chalatenango, recibiendo saludos de todos nuestros hermanos, nuestros ancestros, para llegar luego a la comunidad de Guarjila, que también había sufrido lo mismo. Era las nueve de la noche ya cuando pisaba la caravana llegando a Guarjila, y los hermanos de Guarjila sonaban la campana invitando a sus repobladores y comuni- 
dades vecinas para celebrar la lucha y el triunfo de las comunidades hermanas que habían retornado. Y que fueron muy bien recibidas por el Comité de Comunidades y Repoblaciones de Chalatenango, CCR, con comida y con una gran fiesta popular.

El día siguiente, 16 de agosto, nos dirigimos a San Antonio Los Ranchos, para reconocer nuestras tierras y ubicarnos entre los bosques, el zacate, pedazos de paredes, de techos, y plásticos negros que habían puesto los hermanos de Guarjila para que nosotros pudiéramos ubicarnos y pasar la lluvia. Fueron otros cinco días continuos y duros, que pasamos trasladando las pocas pertenencias que todavía teníamos y por supuesto a nuestra familia, quienes iniciaban una nueva vida crítica bajo enfrentamientos armados, pero toda la comunidad unida y organizada resistíamos las amenazas y capturas de compañeros por el ejército salvadoreño. Y comenzamos la producción agrícola, la reconstrucción en las diferentes áreas de trabajo en nuestra comunidad.

Esta es nuestra verdadera historia, organizada con los mismos principios y fines para alcanzar una revolución; la unidad se logra cuando nace de un mismo principio y va para un mismo fin, ¿existirá todavía unidad, organización, en nuestro pensamiento y corazón?

Luego, fuimos recorriendo las principales calles de Los Ranchos, acompañados de la banda de la alcaldía de Apopa. En cada esquina nos deteníamos, la banda de la alcaldía de Apopa cantaba canciones rancheras y se reventaban cohetes de vara.

A las 10:30 am. comenzó el torneo de futbol, en el cual participaron diversos equipos del oriente de Chalatenango. Los equipos que participaron en este torneo son:

$\begin{array}{ll}\text { Zacamil \#1 (Suchitoto) } & \text { Inglaterra (El Portillo) } \\ \text { Zacamil \#2 (Suchitoto) } & \text { Olimpia Lion (El Portillo) } \\ \text { El Calvario (Los Ranchos) } & \text { Juvenil (Guancora o Ellacuría) } \\ \text { San Luis del Carmen } & \text { Los Ranchos (Los Ranchos) } \\ \text { El CAM (San Salvador) } & \text { Destroyer } \\ \text { Sitio Carnicera \#1 } & \text { Guarjila B (Guarjila) } \\ \text { Sitio Carnicera \#2 } & \text { Ellacuría B (Guancora o Ellacuría) } \\ \text { Arcenal } & \text { Guarjila A (Guarjila) } \\ \text { Indiana (Guarjila) } & \text { Juventud Olímpica (Arcatao) } \\ \text { Juvenil Los Ranchos (Los Ranchos) }\end{array}$

Los equipos jugaron 20 minutos, 10 minutos por tiempo, definiendo el partido en caso de empate a través de penaltis. En este caso, el Juventud Olímpica de Arcatao obtuvo el primer lugar.
Mientras se llevaba a cabo este campeonato, los semicampesinos escuchaban música disco y salsa, aunque predomina la música disco. Luego, ponen música norteña y romántica en español.

A las 4:30 pm. se realiza «el recorrido de la repoblación»: carros, camiones y población a pie se dirige hacia el parque central de Los Ranchos. La caravana lleva el siguiente orden: primero va la población civil, luego va el carro del Alto Comisionado de las Naciones Unidas para los Refugiados (ACNUR) y después van carros y camiones representando a los buses y camiones que venían de Mesa Grande. Algunas personas que se han disfrazado de soldados caminan alrededor de la caravana, los soldados van armados con varas de bambú que simulan fusiles.

En un momento determinado, un retén del ejército de Honduras detiene la caravana, este retén constituye la primera estación para llegar a los Ranchos. El retén no deja salir a la caravana del campamento de refugiados — 7:30 a.m. del 10 de agosto de 1988 - La representante de ACNUR negocia con los militares hondureños. Después de una discusión, se permite que avance la caravana.

Vamos avanzando con música de la repoblación, se van reventando cohetes para simular los tiroteos. Más adelante se detiene la caravana en una segunda estación: la aduana de El Poy de Honduras — 3:30 p.m. del 10 de agosto de 1988_ . Los soldados no dejan pasar a los repobladores pero los representantes de ACNUR negocian con ellos. Se reúnen con los militares hondureños y salvadoreños. La representante de ACNUR dice que los internacionales no pueden ingresar a El Salvador y que los salvadoreños como ya es de noche tienen que quedarse a dormir en la frontera. Luego, el Coronel Ochoa Pérez permite el ingreso de la caravana a El Salvador, pero advierte que el país está en guerra y que al ingresar en el territorio nacional están poniendo en riesgo sus vidas.

La caravana continúa con música del refugio. A las 5:00 p.m. se llega al desvío de Tejutla, en donde se van a despedir de sus compañeros que se dirigen a Teosinte. Sin embargo, sorprendentemente, las autoridades de ACNUR no detienen el carro y se llevan al coordinador general de la repoblación, en un intento para evitar que los repobladores llegaran a sus destinos, Teosinte y 
Los Ranchos, pues suponían que el coordinador general los guiaba hacia estos lugares. No obstante, los repobladores esperan a que regrese su coordinador general -12 de agosto de 1988-. Medardo Gómez, Obispo de la Iglesia Luterana, y los representantes de CNR-CRIPDES, se presentan al desvío de Tejutla para dar su apoyo a los repobladores. Los repobladores permanecen tres días en este desvío, una señora da a luz en la calle - una asistente comenta: «es que así fue, dio a luz en la calle»-.

Las condiciones son inhumanas, ya tienen cinco días viajando, los animales se están muriendo, pero la gente aguanta. Finalmente, se permite que los repobladores continúen su camino hacia el oriente de Chalatenango. Al llegar a Guarjila, los semicampesinos de Guarjila reciben a los repobladores de Los Ranchos. Los de Guarjila ofrecen las palabras de bienvenida y abrazan a los recién llegados —esto se realiza en la Plaza Central de Los Ranchos-.

Los de Guarjila ofrecen agua y comida a los de Los Ranchos y suenan las campanas de la iglesia. Luego, ponen música bailable, tipo cumbia, y la gente se pone a bailar. Algunas personas están disfrazadas de guerrilleros, con el objeto de representar el reencuentro de los guerrilleros con los repobladores, que a final de cuentas son sus familiares.

Luego, revientan cohetes con el objeto de representar los combates que se daban en ese tiempo entre soldados y guerrilleros, el que lleva el cañón 90 le pone cohetes en su interior para simular el disparo del cañón. El Alcalde de Los Ranchos explica cómo se encontraba la comunidad cuando ellos llegaron.

Ahora, el excomandante guerrillero Amilcar, El Cabo, realiza una «parada militar» con el pelotón exguerrillero. Los asistentes cantan el himno del FMLN y al terminar se ofrecen diversos testimonios.

A las 8:00 pm. se presenta en la Casa Comunal de Los Ranchos el grupo Nuevas Vidas Teatro de Guarjila, con la obra «Recordando el Pasado, Viviendo el Presente». Inicia con la siguiente frase: «al inicio de nuestra historia la tierra no era de nadie, pero nuestro pueblo fue despojado y comenzó la represión y las masacres».
La obra habla de las masacres en las comunidades del oriente de Chalatenango y de la lucha popular impulsada por estas poblaciones. Luego, se representa la huida hacia Mesa Grande, Honduras. Después, se habla de la vida en el campamento de refugiados, en particular el trabajo en los talleres: «si no hubiéramos venido a Mesa Grande no habríamos aprendido a hacer estos trabajos: cebaderas, matatas, y todo eso, pero es gracias a la organización que tenemos y a la educación», puntualizó una actriz.

Luego, los actores citan a una asamblea y se plantea la idea de regresar a El Salvador. Todos los actores apoyan esta idea. Entonces, se representa el viaje de retorno a Los Ranchos. Los de Guarjila se preparan para recibir a los repobladores de Los Ranchos, limpiando la calle que conduce a este municipio. Finalmente, llegan a Los Ranchos y se plantea la necesidad de mantenerse bien organizados; doña Teodora le agradece a Dios por haberlos regresado a su tierra natal.

A continuación, la obra plantea la situación del presente: se presenta a la comunidad con proyectos de desarrollo, calles pavimentadas, escuela e instituto, etc. El presente es alcohol, discotecas, individualismo y materialismo, pero entonces un actor le pregunta a otro: «¿ya se te olvidó lo bueno de la vida de antes a pesar de lo sufrido?

«-No - le contesta el otro-, antes todo era para todos, pero eso se acabó, a mí sólo me interesa todo para mí.

— «Esta es nuestra historia —enfatiza un actor-,porque cambia, todo cambia, y que cambie no es extraño, pero pueblo que olvida su historia está muerto».

Con este pensamiento termina la obra de teatro. Luego, se presenta el payaso Talhuashteso y Lola La trailera, y ahí termina este día.

El día siguiente, 12 de octubre, se realiza la misa de la comunidad. El padre Miguelito, el párroco del municipio de Arcatao, en el oriente de Chalatenango, quien acompañó a los semicampesinos en su lucha revolucionaria, presidió la misa, acompañado del párroco de Los Ranchos y del Padre Rutilio Sánchez. La iglesia estaba adornada con los colores verde y blanco, colores que simbolizan esperanza. 
Agradecerles porque esta fecha histórica para nosotros, son fechas grandes que se llevan en el corazón, nunca se olvidan, verdá, porque es la acción de Dios en su pueblo, para la ayuda de su pueblo, y que nos seguirán guiando estos acontecimientos, ojalá siempre».

Yo recordaba el salmo que dice: cuando se iban iban llorando, y cuando regresaban regresaban cantando, con signos de alegría... estaba haciendo memoria, todos nos remontamos este día a todo ese proceso, verdá, que culmina con el regreso a la patria, y uno se va recordando de todo lo previo, de todo el dolor, el sufrimiento y la esperanza, de las guindas, ${ }^{12}$ verdá, y todo el calvario que se tuvo que pasar, y luego la vivencia dentro del campamento de refugiados, que sé yo, a lo largo del camino, las familias que nos tendieron su solidaridad.

Entonces, uno va recordando todos esos momentos, pero más grandioso el momento en que comienza a hablarse del regreso, aun cuando la guerra estaba en una de sus fases de definición... y la primera lectura que hoy proclamamos dice: que la noche de la liberación pascual fue anunciada con anterioridad a nuestros padres, para que se confortaran al reconocer la firmeza de las promesas en que habían creído, verdá, y sólo los hombres y las mujeres de fe, que tenían enraizada su fe en Dios sabían que cuando Dios pone su palabra, cuando Dios camina con su pueblo no le falla, por eso podríamos decir ahora nosotros, bueno, bienaventurados ustedes que han podido ver todos estos cambios, porque muchos quedaron en el camino, en el camino de la guinda, en el camino buscando un lugar seguro, en el camino del campamento... sin embargo, murieron con esa fe y esa confianza en Dios de que ese sufrimiento no iba a ser eterno y de que esto iba a cambiar.

Por eso la pregunta que tenemos que hacernos en ocasión de celebrar estos diecinueve años, que ya son diecinueve años de juventud, vea... ¿dónde está el corazón de cada uno de nosotros hoy?, ¿el corazón de cada uno de nosotros, el corazón de la comunidad?, ¿el corazón de nuestros mártires?, vea, ¿dónde estamos hoy?, ¿estamos satisfechos con lo que hemos avanzado, logrado, o a lo mejor nos hemos desviado?... fijense ustedes que en el Antiguo Testamento, cuando la comunidad regresó del exilio y venía con la alegría de regresar a su tierra... comenzó a levantar su casita, a levantar la producción y a ofrecer la primicia, dice voy a ofre-

${ }^{12}$ Guinda: huida rápida de un lugar por la persecución del ejército. cer esta primicia al Dios que me ha acompañado, que me salva y que me sigue acompañando, a no olvidar el compartir... y aquel pueblo que regresó sí vamos a reconstruir nuestro templo, porque aquí en este lugar venimos a encontrarnos en comunidad con nuestro Padre Dios, el templo de la comunidad organizada, entonces, ¿estamos nosotros reconstruyendo realmente en estos diecinueve años la comunidad, la unidad, el compartir, o a lo mejor nos ha ido tragando ese monstruo de siete cabezas: el poder, el consumismo, el tener, el egoísmo, las cosas materiales?

¿Dónde nos encontramos en este momento?, porque el panorama de la realidad no nos dice que hayamos construido todavía los sueños esperados, pero sí nos dice que avanzamos hacia esa meta común. ¿Qué estamos haciendo día a día para que esa nueva sociedad sea posible?, que no va a ser fruto de un decreto... no es verdad, la nueva sociedad va naciendo en el corazón de cada uno de nosotros y ahí donde estamos viviendo y construyendo la familia debe ser la familia nueva, la comunidad nueva, ¿qué tanto estamos construyendo esa comunidad aquí entre nosotros?, ¿donde estamos?, ¿nos hemos acercado más, nos hemos unido más, nos hemos organizado más o nos hemos dividido más y cada uno está rezando a su Santo por su lado?

Los poderosos están interesados en borrar nuestra memoria, lo que ha pasado, pero ni ellos se lo creen, tienen todas las mejores propagandas por la radio, por la televisión, por el sistema educativo, y por muchos sistemas que se van inventando, para que el pueblo olvide su memoria histórica, pero no puede ser, va contra Dios, porque lo que celebramos precisamente aquí, el banquete, la eucaristía, Dios dice: hagan esto en memoria mía, que es su presencia viva entre nosotros...

El sacerdote continúa hablando del compromiso de los cristianos con la construcción de un nuevo tipo de sociedad y de cultura, una sociedad solidaria, justa y equitativa. Enfatiza la lucha contra las nuevas amenazas, la explotación de las compañías mineras, la construcción de las represas y de la Longitudinal del Norte. «Todos estos son proyectos de los poderosos que empobrecen más a nuestro pueblo» —concluye.

A las 19:30 horas se presenta el grupo o Tiempos Nuevos Teatro (TNT) de Los Ranchos, con siete danzas:

- Suite de las hadas, con música de Tchaikovski 
- Suite de Vírgenes, con música de Vangelis

- Cordón umbilical, con música de Vangelis

- Naturaleza Morta, con música del grupo canadiense Destroyer

- Presagio, con música del grupo costarricense Malpais

- Desde que te vi, no te quiero

- Cosas de la vida

Luego, se presentó un grupo que realizó una mezcla de danza y piruetas en el aire. Finalmente, el ritual terminó con un baile con el grupo Renacer de Guarjila.

\section{INTERPRETACIÓN}

En este ritual pueden observarse las tres fases de todo ritual comunitario, a saber: ( $i)$ la de separación, representada por la inauguración de la sala de arte Hermana Sofía, las actividades culturales del 10 de agosto por la noche en el parque central y la alegre alborada. Las primeras dos actividades, realizadas el 10 de agosto, corresponden a una fase de preparación, en donde los semicampesinos se disponen a la realización del ritual. Esta fase constituye una subfase de la de separación. La alegre alborada constituye la ruptura propiamente dicha, indica el inicio del ritual; (ii) la fase nuclear o liminar, en la cual se realiza el torneo de futbol, se representa el viaje de regreso al municipio, se presenta el teatro de Guarjila y se celebra la misa de la comunidad; y (iii) la fase de reintegración, en la cual se presenta el grupo Tiempos Nuevos Teatro de Los Ranchos, y termina con un baile amenizado por el grupo Renacer de Guarjila.

En la fase nuclear, las actividades centrales son: el torneo de futbol, el recorrido de la repoblación y la misa de la comunidad. Los símbolos dominantes son el trofeo del campeonato de futbol y el parque central de la comunidad.

El trofeo del campeonato de futbol refleja la asimetría creada a través de este torneo, en donde se establece un ganador y un conjunto de perdedores. Como lo resalta Lévi-Strauss (1984 [1962]: 58), «el juego se nos manifiesta como disyuntivo: culmina en la creación de una separación diferencial entre jugadores individuales o entre bandos, que al principio nada designaba como desiguales. Sin embargo, al fin de la partida se distinguirán ganadores y perdedores... En el caso del juego la simetría está, por lo tanto, preordenada y es estructural, puesto que se deriva del principio de que las reglas son las mismas para los dos equipos. La asimetría es engendrada, se deriva inevitablemente de la contingencia de los acontecimientos, dependen estos de la intención, del azar o del talento».

En este sentido, el juego de futbol reproduce el ideal del sistema capitalista: se establece una competencia entre grupos de 11 jugadores que parten de las mismas condiciones, las reglas son iguales para todos, y el objetivo del campeonato es establecer una jerarquía: al final habrá un equipo ganador, un segundo lugar, y un conjunto de perdedores. La jerarquía es engendrada por el desarrollo de los acontecimientos, que dependen básicamente del esfuerzo y de la habilidad de las personas.

Por su parte, en la sociedad capitalista la diferencia es estructural; sin embargo, mantiene como imaginario colectivo que todos los individuos parten de condiciones iguales, que las reglas son las mismas para todos, y que las jerarquías se establecen por el esfuerzo y el talento de las personas.

Asimismo, en el juego de futbol se reproduce simbólicamente el funcionamiento de una empresa capitalista, el accionar de un equipo depende de una combinación de trabajo en equipo con la habilidad individual de los jugadores. Además, los jugadores deben anotar goles en un tiempo determinado, en este caso 20 minutos, recreando el condicionamiento que la empresa capitalista tiene del tiempo: la empresa debe producir el máximo posible en el menor tiempo. De la misma manera, en el partido de futbol los jugadores deben anotar el máximo de goles en un tiempo definido, lo que hagan fuera de ese tiempo ya no cuenta.

Ahora bien, todo equipo de futbol tiene una dirección definida, en los equipos profesionales existe un director técnico y un capitán, de la misma manera que en las empresas capitalistas existe una dirección definida con jerarquías establecidas; sin embargo, en los equipos que participaron en el Aniversario de la Repoblación de 
Los Ranchos la dirección está menos definida; de hecho, la dirección descansa en los jugadores más habilidosos, quienes se constituyen de facto en los capitanes o líderes de los equipos. Esta última característica puede interpretarse como el contenido campesino que mantiene la cultura local de Los Ranchos.

En síntesis, el campeonato de futbol, uno de los eventos simbólicos centrales de la fase nuclear de este ritual, transmite como uno de sus valores principales el sentido de competencia capitalista, al coadyuvar, en el plano simbólico, a la integración de los semicampesinos revolucionarios a la sociedad nacional y global.

Por otra parte, el campeonato enfrenta a equipos de diversas comunidades y municipios del oriente de Chalatenango, de Suchitoto, una zona aledaña al oriente de Chalatenango, e incluso a uno de San Salvador. En este sentido, reafirma el principio de identidad municipal, precisamente porque la identidad sociocultural está basada en una relación de oposición y conflicto entre el nosotros y los otros, en este caso entre el municipio de San Antonio de Los Ranchos y el resto de comunidades y municipios del oriente de Chalatenango, e incluso municipios de Suchitoto y de San Salvador, y el juego de futbol constituye una representación simbólica de estas relaciones de oposición y conflicto.

Es interesante observar que la mayoría de los equipos de futbol son del oriente de Chalatenango; solo participaron dos equipos de Suchitoto y uno de la capital del país. Esto indica que los pobladores de Los Ranchos construyen su identidad en primer lugar en oposición al resto de las comunidades y los municipios del oriente de Chalatenango, con quienes mantienen una interacción social cotidiana, antes que con otras áreas del país, ya que con ellas mantienen relaciones más distantes.

El hecho de que se hayan presentado dos equipos de Suchitoto y uno de la ciudad de San Salvador ubica a Los Ranchos en la dinámica sociocultural de la nación, como formando parte de la sociedad nacional.

Así, el contenido de este símbolo dominante puede esquematizarse de la siguiente manera:
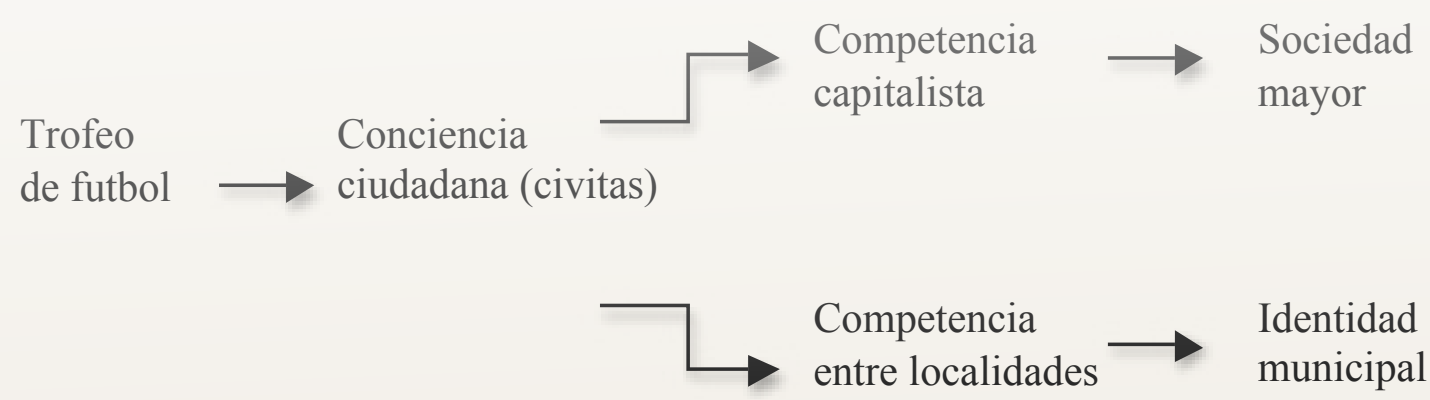

Ronald Grimes (1981) ha mostrado lo importante que es develar los tipos de conciencia social que intervienen en la construcción de los símbolos rituales, pues condicionan el contenido que crean y recrean los símbolos. En nuestro caso particular, el trofeo de futbol es un símbolo de la conciencia ciudadana (civitas), la conciencia de pertenencia al municipio, lo cual establece la autonomía del municipio frente a la sociedad mayor, no obstante que esta misma conciencia ciudadana recrea el valor de la competencia capitalista y establece la relación del municipio con la sociedad nacional y global. Así, la autonomía del municipio no es absoluta, no se trata de un municipio aislado, sino que en parte está integrado a la sociedad capitalista nacional y global. Esta misma conciencia ciudadana construye el valor de la competencia entre localidades, y reafirma el valor de la identidad municipal, el cual está basado en la oposición entre el nosotros y los otros.

El segundo símbolo dominante es el Parque Central, que constituye el corazón del municipio, es el lugar a donde llegaron los repoblado- 
res en su largo viaje de retorno a San Antonio de Los Ranchos. Es por ello que en la peregrinación ritual realizada por los semicampesinos de Los Ranchos el día 11 de agosto de 2007, el punto de llegada fue el Parque Central, establecido como un lugar sagrado y la meta que se proponían alcanzar los peregrinos.

En efecto, el llamado «recorrido de la repoblación» constituye una peregrinación ritual. Es una actividad simbólica que va de lo cerca a lo lejos, como lo señala Ronald Grimes (1981), y el lugar sagrado es el punto de llegada del peregrino, la tierra prometida en donde van a construir un nuevo tipo de sociedad y de cultura.

Este símbolo puede esquematizarse así:

Parque Central $\rightarrow$ conciencia ciudadana-conciencia oficial-conciencia revolucionaria $\rightarrow$ corazón del municipio $\rightarrow$ memoria histórica $\rightarrow$ organización social $\rightarrow$ lucha en contra del capitalismo dominante $\rightarrow$ construcción de un nuevo tipo de sociedad y de cultura.

El parque central es un símbolo de la alianza entre la conciencia ciudadana, la conciencia oficial (la conciencia del Estado local) y la conciencia revolucionaria, con base en la cual se establece la autonomía del municipio frente a la sociedad más amplia y sus instituciones, incluso frente al FMLN como partido político y frente a la Iglesia católica.

En este sentido es importante subrayar que la conciencia revolucionaria de los semicampesinos de Los Ranchos se refiere a la conciencia que creció en el marco del FMLN como movimiento social, en alianza con la corriente del catolicismo popular de la opción preferencial por los pobres, y no tanto a los discursos y los simbolismos oficiales del FMLN como partido político y de la Iglesia católica como conciencia religiosa oficial o ecclesia. ${ }^{13}$

\footnotetext{
${ }^{13}$ Es importante aclarar que los semicampesinos de Los Ranchos establecen una clara distinción entre el FMLN como organización política, la organización político-militar que acogió al movimiento campesino que ellos construyeron, y el FMLN como partido político, al cual le tienen muchas críticas, pues consideran que no ha satisfecho totalmente
}

Esta alianza de la conciencia ciudadana y de la conciencia oficial con la conciencia revolucionaria reivindica la importancia de la memoria histórica local y de la organización política y social del municipio, las cuales son concebidas como armas en contra de la sociedad capitalista dominante y, por tanto, recursos para la construcción de un nuevo tipo de sociedad y de cultura.

Ahora bien, la peregrinación ritual de los semicampesinos de Los Ranchos es vivida como sacrificio; el dolor y el sufrimiento son evidentes a lo largo del recorrido, estableciendo las tres caídas (o estaciones u obstáculos) de la pasión de Jesucristo. Incluso cuando llegan al Parque Central, los semicampesinos representan un enfrentamiento entre la guerrilla y el ejército, rememorando las duras condiciones en que encontraron su tierra prometida. Este sentido de sacrificio o martiriológico, como diría Martín Baró (2008a, 2008b), representa un fundamento simbólico fuerte para el compromiso que los semicampesinos han adquirido en la construcción de un nuevo tipo de sociedad y de cultura.

De hecho, los pobladores del oriente de Chalatenango recuerdan este periodo como positivo. La obra del grupo de Guarjila Nuevas Vidas Teatro termina, como vimos antes, con el siguiente diálogo: un actor le pregunta a otro:

— ¿Ya se te olvidó lo bueno de la vida de antes a pesar de lo sufrido?

- No - le contesta el otro-,antes todo era para todos, pero eso se acabó, a mí solo me interesa todo para mí.

Este diálogo muestra el valor positivo del sacrificio que los semicampesinos experimentaron a lo largo de todo el periodo del conflicto militar, mientras valora negativamente las condiciones actuales, en las que si bien tienen mejores condiciones de vida han penetrado en ellos los valores del capitalismo: individualismo y materialismo.

También el sacerdote que ofició la misa resalta el valor del sacrificio y del martirio para la construcción de una sociedad más solidaria y

sus expectativas. La organización política y social actual de Los Ranchos (y, en general, de las comunidades y de los municipios del oriente de Chalatenango) está condicionada en gran medida por el FMLN como organización política o movimiento social, no obstante que también el FMLN como partido político está condicionando la dinámica sociocultural de estas poblaciones. 
equitativa. El sacrificio experimentado a lo largo del conflicto bélico generaba sentimientos de solidaridad y ayuda mutua, mientras que las condiciones actuales empujan a la gente a ser más individualista y materialista, es decir, a desviar a los semicampesinos del camino trazado.

\section{CONCLUSIÓN}

A manera de conclusión, puede establecerse que este ritual que conmemora el retorno de los semicampesinos revolucionarios a Los Ranchos no constituye un simple mecanismo que oculte las diferencias y los conflictos internos del municipio, como lo sostiene Irina Silberg (2011) a propósito de un cantón del municipio de Las Vueltas (en el oriente de Chalatenango), sino que también transmite una serie de valores que orienta a los sujetos sociales a la construcción de un nuevo tipo de sociedad y de cultura.

En este sentido, como lo ha establecido Paul Ricoeur (2004), el discurso de la memoria colectiva e histórica, si bien hace referencia al pasado, construye un sentido sobre el pasado, el presente y el futuro, proporcionando valores y concepciones que son pertinentes para el presente y que orientan la acción social hacia el futuro.

En este caso específico, el ritual de Aniversario de la Repoblación de Los Ranchos si bien se construye con base en las necesidades y las exigencias de la sociedad presente, de la sociedad en la cual se realiza el ritual (Los Ranchos 2007), crea y recrea un conjunto de valores que son pertinentes tanto para el desenvolvimiento de esta sociedad en el momento en el que se realiza el ritual —sentido de competencia capitalista y de competencia entre localidades, sentido de lucha en contra del sistema capitalista dominante, sentido de sacrificio, sentido de unidad y de cohesión social - como para la acción social en el futuro, la cual tiene que ver con la utopía del grupo, a saber: la construcción de una sociedad más solidaria, equitativa y participativa. Si bien es cierto que en Los Ranchos se han obtenido avances importantes en esta dirección siempre representa una proyección hacia el futuro, ya que constituye un proyecto en constante construcción.

\section{FUENTES DE CONSULTA}

Bajtín, Mijaíl, 1992, Estética de la Creación Verbal, México, Siglo XXI Editores.

Grimes, Ronald L., 1981, Símbolo y Conquista. Rituales y Teatro en Santa Fe, Nuevo México, México, FCE.

Lévi-Strauss, Claude, 1984, El Pensamiento Salvaje, México, FCE.

Martín Baró, Ignacio, 2008a, Acción e Ideología. Psicología Social desde Centroamérica, San Salvador, UCA.

—, $2008 b$, Sistema, Grupo y Poder. Psicología Social desde Centroamérica (II), San Salvador, UCA.

Ministerio de Economía, Dirección General de Estadística y Censos, y Gobierno de El Salvador, 2008, VI Censo de Población y V de Vivienda 2007.

Ricoeur, Paul, 2004, La Memoria, La Historia, El Olvido, Buenos Aires, FCE.

Silber, Irina Carlota, 2011, Everyday Revolutionaries. Gender, Violence and Disillusionment in Postwar El Salvador, EUA, Rutgers University Press.

Tischler Visquerra, Sergio, 2005, Memoria, Tiempo y Sujeto, Guatemala, Instituto de Ciencias Sociales y Humanidades (BUAP)/FyG.

Turner, Víctor, 1980, La Selva de los Símbolos, Madrid, Siglo XXI Editores.

Turner, Víctor, 1982, From Ritual To Theatre, Nueva York, P.A.J.P.

Weber, Max, 1981, Economía y Sociedad, México, FCE
Fecha de recepción: 26 de marzo de 2014 Fecha de aceptación: 28 de octubre de 2014 